shall get the result stated. The curve obtained in this way is in reality identical with the other curves. By these four methods then we arrive at the conclusion that the last colour to be extinguished is the sensation which when strong gives the sensation of violet, but which when feeble gives a blue-grey sensation.

One final experiment I may show you. It has been remarked that moonlight passing through painted glass windows is colourless on the grey stone floor of a cathedral or church.

We can imitate the painted glass and moonlight. Here is a diaper pattern of different coloured glasses, and by means of the electric light lantern we throw its coloured pattern on the screen. The strength of moonlight being known, we can reduce the intensity of the light of the lamp till it is of the same value. When this is done it will be seen that the pattern remains, but is now colourless, showing that the recorded observations are correct, and I think you are now in a position to account for the disappearance of the colour.

I have now carried you through a series of experiments which are difficult to carry out perfectly before an audience, but at any rate I think you will have seen enough to show you that the first sensation of light is what answers to the violet sensation when it is strong enough to give the sensation of colour. The other sensations seem to be engrafted on this one sensation, but in what manner it is somewhat difficult to imagine. Whether the primitive sensation of light was this and the others evolved, of course we cannot know. It appears probable that even in insect life this violet sensation is predominant, or at all events existent. Insects whose food is to be found in flowers seek it in the gloaming, when they are comparatively safe from attack. Prof. Huxley states that the greater number of wild flowers are certainly not red, but more or less of a blue colour. This means that the insect eye has to distinguish these flowers at dusk from the surrounding leaves, which are then of a dismal grey; a blue flower would be visible to us whilst a red flower would be as black as night. That the insects single out these flowers seems to show that they participate in the same order of visual sensations. I venture to think, without adopting it in its entirety, that these results at all events give an additional probability as to the general correctness of the Young-Helmholtz theory of colour vision. Where the seat of colour sensation may be is not the point, it is only the question as to what the colour sensations make us feel which the physicist has to deal with. The simpler the theory, the more likely is it to be the true one, and certainly the Young-Helmholtz theory has the advantage over others of simplicity.

\section{"THE EPIGLOTTIS:"1}

FROM an anthropotomical point of view the epiglottis had for a long time been generally looked upon as a kind of sentinel for the protection of the upper air passages, when Rückert's comparative anatomical observations showed that the human epiglottis greatly differed from that of mammals, in so far as its relations to the soft palate were entirely altered, and that its physiological conditions pari passu had undergone important modifications. The new points of view thus obtained induced Gegenbaur to study the comparative anatomy of the epiglottis and its relations to the larynx, and the present volume is the outcome of his investigations.

The inquiry being undertaken from a morphological point of view the author begins with a study of the different forms of the epiglottis or epiglottoid structures in low classes of animal life. He next discusses the mammalian epiglottis and its relations to the soft palate. The con-

1 "Die Epiglottis," Vergleichend anatomische Studie, by Carl Gegenbaur, with two plates, \&c. (Leipzig: Wilh. Engelmann, r8g2.) clusions here arrived at, and which concern the act of deglutition in the lower classes of mammals, lead to a consideration of other organs of the oral cavity, and to an attempt at establishing a connection between these and the apparatus consisting of the epiglottis and soft palate. This in turn induces a minute investigation of the structure of the epiglottis, and of its relationship to the framework of the larynx and the general structure of the respiratory organs in the lowest forms of animal life. In the last chapter the author summarizes the results obtained by his comparative studies and throws out such suggestions concerning the origin, development, and function of the epiglottis as would seem justified by his researches.

Brief as this survey of the course of Gegenbaur's essay necessarily has been, it will be sufficient to show that it is quite impossible to give in the space of a short review a detailed analysis of its contents. Conclusions derived from the synthetic conception of an enormous number of single observations, which extend over a large part of the entire animal kingdom, can only be properly appreciated by a study of the original, and this may be warmly recom. mended.

The final and most important conclusion arrived at by the author may be briefly summarized as follows :-

Whilst as high up in the scale as in the sauropsidx, parts of two branchial arches only contribute towards forming the primary hyoid, three more arches are added in the mammals. Two of these growing together form the transition into the thyroid, which becomes intimately connected with the larynx.

The mammalian larynx, however, has received a further addition, viz. the epiglottis, the cartilage of which can only be looked upon as the further development of the fourth branchial arch, which in fishes still serves its primitive function, and in the amphibia appears in a rudimentary form. The exact manner in which this rudiment passes over into the supporting organ of the epiglottis in mammals is, on the whole, still obscure. So much, however, is certain, that the cartilage of the epiglottis is not a product of mucous membrane, but a genuine part of the skeleton, and that it communicates its supporting function to the whole of the epiglottis, which serves as well the purpose of keeping the air-passages open as of protecting the vestibule of the larynx.

From this final conclusion it will be seen that, according to Gegenbaur, the rôle of the epiglottis in its highest development is purely a respiratory and protective one.

Pathological observation in man does not admit of these functions of the part being looked upon in any way as indispensable for the existence of the individual. Total loss of the epiglottis has often been observed in various diseases, without the patients either suffering from dyspnœe or from increased liability to the entrance of foreign bodies into the lower air-passages, the constrictor vestibuli laryngis (Luschka) in such cases vicariously taking its function. The supposed phonatory rôle of the epiglottis, upon which much stress is laid by some eminent singing masters (e.g. Stockhausen), inasmuch as they maintain that it influences, according to its more erect or morc horizontal position, the "timbre" of the singing voice, is not even mentioned in Gegenbaur's essay. Thus many points connected with this subject still demand elucidation. Still it is impossible to withhold the expression of admiration and of gratitude to the author of the present work for his patient and extensive researches in a very obscure field of comparative anatomy.

\section{NOTES.}

ON Saturday the British Eclipse Expedition to West Africa arrived safely at Bathurst. The Alecto was there, ready to convey the party up the Salum River to the selected site.

NO. I 223 , VOL. 47] 